\title{
Particle size distribution and dissolution properties of metals in cyclone fly ash
}

\author{
${ }^{1 *}$ H. Rönkkömäki; ${ }^{2}$ R. Pöykiö; ${ }^{3}$ H. Nurmesniemi; ${ }^{4}$ K. Popov; ${ }^{5}$ E. Merisalu; ${ }^{6}$ T. Tuomi; ${ }^{7}$ I. Välimäki \\ ${ }^{1}$ Finnish Institute of Occupational Health, Aapistie 1, FI-90220 Oulu, Finland \\ ${ }^{2}$ City of Kemi, The Town Planning and Building Committee, Environmental Research Division, Valtakatu 26, FI-94100 \\ Kemi, Finland \\ ${ }^{3}$ Stora Enso Oyj, Veitsiluoto Mill, FI-94800 Kemi, Finland \\ ${ }^{4}$ Moscow State University of Food Technologies, Volokolamskoye sh. 11, Moscow 125080, Russia \\ ${ }^{5}$ Department of Public Health, University of Tartu, St Ravila 19, 50411 Tartu, Estonia \\ ${ }^{6}$ Finnish Institute of Occupational Health, Arinatie 3, FI-00370 Helsinki, Finland \\ ${ }^{7}$ Suomen Ympäristöpalvelu Oy, Kiilakiventie 1, FI-90250 Oulu, Finland \\ Received 13 June 2008; $\quad$ revised 29 June 2008; accepted 22 July 2008; available online 1 September 2008
}

\begin{abstract}
The particles in the examined cyclone fly ash were all smaller than $0.25 \mathrm{~mm}$. in diameter, and particles smaller than $0.075 \mathrm{~mm}$. in diameter accounted for $88.4 \%$ of the ash weight. This result indicates that cyclone fly ash consists of particles with a small diameter. The metals in the cyclone fly ash were enriched in small particles. The highest concentrations for zinc, copper, lead, cadmium and molybdenum in the cyclone fly ash were found in the smallest particle size fraction $(<0.075 \mathrm{~mm}$.) and for Barium, chromium, nickel, Vanadium and Cobalt in the second to smallest particle size fraction $(0.075-0.125 \mathrm{~mm}$.). From an environmental and toxicological standpoint, the smallest particles are of the greatest concern when ash is handed at landfill disposal sites (transport and disposal especially in stormy weather conditions), and some studies have reported risks to workers from prolonged exposure to ash. The results of the comparison of various dissolution methods for metals showed that the digestion procedures with nitric acid alone (USEPA 3051) or with a mixture of nitric acid + hydrogen peroxide (USEPA 3050B) slightly underestimated the metal concentrations in the cyclone fly ash. Although the use of hydrofluoric acid is often necessary for the determination of a number of elements associated with siliceous minerals, its use can result in loss of trace elements during dissolution.
\end{abstract}

Key word: Bark, forest residues, grate-fired boiler, waste, wood

\section{INTRODUCTION}

Most of the analytical methods used for metals determination in environmental materials, such as ash, soil, sediments, and sludge, require decomposition of the sample. Hence, when the analytical methods require dissolution of the sample, sample preparation, in addition sampling, is the analysis step with the greatest effect on the uncertainty of the final results (Filgueiras et al., 2002). The efficiency of the mineralization procedure is crucial for obtaining correct results. This is especially important in the determination of metals in environmental studies. To be effective, sample $\triangle$ *Corresponding Author Email: hannu.ronkkomaki@ttl.fi Tel:+ 358030474 6030; Fax: +358 0304746000 digestion methods must efficiently decompose the sample matrix so that the analytes of interest are completely released and solubilized, in other words that total decomposition of the sample is achieved. Moreover, the analytes must be in a suitable form for the analytical method. Nowadays, microwave ovens are widely used for total decomposition of environmental samples. However, sample preparation remains a major factor contributing to the uncertainty of the final results. In Finland, environmental legislation requires the operator to be aware of the amount and composition of the emissions, as well as the efficiency of the abatement methods/equipment used, and also 
of the impacts on the environment caused by the operations of the pollutant sources. In Finland, small-scale (3-50 MW) power plants are commonly used for municipal district heating especially in rural areas, but also in many small towns and urban areas. These plants burn mostly forest residues (i.e. wood chips, sawdust, bark) and peat. However, the disadvantage of energy production by burning fuels such as wood and peat is that it produces a considerable amount of ash, which requires handling, e.g. in the form of landfill disposal. When assessing the effects of ash handling, physico-chemical properties, such as particle size fractions and the possible occurrence of toxic minerals and/or metals and their concentrations, are important factors for hygienists and analytical chemists in characterizing the possible health effects of ash handling at the workplaces, such as incineration plants and disposal sites (Hlavay et al., 1992; Osán et al., 2002).

When assessing the effects of ash disposal on the air environment (impact monitoring), it is necessary to obtain the total metal concentrations. The widely used sample decomposition procedures employing reagents such as $\mathrm{HNO}_{3}$ alone or $\mathrm{HNO}_{3}+\mathrm{H}_{2} \mathrm{O}_{2}$ do not always ensure complete decomposition. Reaching a total decomposition of the sample is a major requirement, especially for the environmental authorities, because the knowledge of both total and leachable concentrations of pollutants in samples is needed when environmental impacts of industrial activities are assessed (Lamble and Hill, 1998). For example, a digestion method that underestimates metal concentrations in airborne particles will not produce correct results for impact monitoring. This, in turn, causes errors when calculating metal concentrations in the air and results in incorrect information about the effects of industrial operations (e.g. ash handling) on the air environment.

The purpose of this study was to obtain information about the main important physical and chemical properties (i.e. pH, LOI, TOC, electrical conductivity, particle size distribution) in the cyclone fly ash originating from the small-scale (6 MW) municipal district heating plant of Keminmaan Energia Oy, at Keminmaa, Northern Finland, which incinerates forest residues (i.e. wood chips, sawdust and bark). In addition, metal (Ba, Zn, Cr, Cu, Pb, Ni, V, Cd, Co and Mo) concentrations for different particle sizes in the cyclone fly ash were determined and assessed the ability of different dissolution methods to release metals in ash. This study is part of a major project carried out in northern Finland between 2000 - 2008, in which various wet digestion decomposition methods and extraction tests are used in assessing the efficiency of the mineralization procedures to release of metals in environmental samples and process residues (Nurmesniemi et al., 2005; Pöykiö and Perämäki, 2003; Pöykiö et al., 2000, 2004 and 2005).

\section{MATERIAL AND METHODS}

\section{Sampling}

The cyclone fly ash investigated in this study was obtained from the municipal district heating plant (6 MW) of Keminmaan Energia Oy., which uses a gratefired boiler for incinerating forest residues (i.e. wood chips, sawdust, bark). Approximately $60 \%$ of the wood incinerated in the plant is hardwood, such as birch (Betula verrucosa) and willow (Saliz spp.), and approximately $40 \%$ is softwood, such as Scots pine (Pinus sylvestris).

The cyclone fly ash was sampled from a cyclone that is used to reduce the emissions of flue gas particles. There are no electrostatic precipitators in the plant. The cyclone fly ash is the ash fraction that has been carried through the flue gas channels into the cyclone and precipitated there.

Technically speaking, cyclone ash is the ash fraction that has been trapped in the cyclone. Ash can be sampled from the cyclone only once or twice a year during maintenance and repair shutdowns at the plant. In Finland, many small municipal district heating plants incinerate wood waste during the warmer season (April to November) and peat during the winter (December to March).

The ash was sampled on November 2007, and thus the cyclone fly ash investigated in this study originates from the incineration of wood waste. The sampling period represented normal process conditions at the plant. A coning and quartering method was applied repeatedly to reduce the ash sample to a size suitable for laboratory analysis. After sampling, the sample was stored in a polyethylene bottle in a refrigerator $\left(+4{ }^{\circ} \mathrm{C}\right)$ until analysis. The incineration temperature inside the boiler (furnace) is ca. 800 to $1100^{\circ} \mathrm{C}$. After the boiler, the temperature of the flue gas is rapidly cooled, and the flue gas leaves the plant at a temperature of 130 to $150{ }^{\circ} \mathrm{C}$. 
Determination of the physical and chemical properties of cyclone fly ash

The $\mathrm{pH}$ and electrical conductivity (EC) of the cyclone fly ash was determined by a combination $\mathrm{pH} /$ EC analyser equipped with a Thermo Orion Sure Flow pH electrode (Turnhout, Belgium) and a Phoenix conductivity electrode with a cell constant of 1.0 (Phoenix Electrode Company, USA). Determination of the $\mathrm{pH}$ and EC were carried out according to the European standard SFS-EN 13037 (SFS-EN, 2000a) at a solid to liquid (S/L) ratio of 1:5 (v/v). Determination of dry matter content (DMC) of the cyclone fly ash was performed according to the European standard SFSEN 12880 (SFS-EN, 2000b), according to which the sample must be dried overnight to a constant mass in an oven at $105^{\circ} \mathrm{C}$.

The loss-on-ignition (LOI) value was determined according to the European standard SFS-EN 12879 (SFS-EN, 2000c): oven-dried $\left(105^{\circ} \mathrm{C}\right)$ sample was drydigested overnight in a muffle furnace (Box Furnace, Lindberg, Blue $\mathrm{M}$, Asheville, USA) at $550{ }^{\circ} \mathrm{C}$. Determination of the total organic carbon (TOC) content in the ash sample was carried out according to the European standard SFS-EN 13137 (SFS-EN, 2001) using a LECO CHN-600 analyser (Leco Inc., USA): the sample was combusted and the evolved carbon dioxide was measured by infrared spectrometry.

Determination of metals distribution in different particle size fractions

For the determination of metals distribution in different particle size fractions, the ash was sieved on an automatic sieve shaker (Retsch Virbo, Haan, Germany). The cyclone ash was dry-sieved through stainless-steel sieves using a stack of nested sieves (DIN 4188, Retsch 5657, Haan, Germany) with the following particle sizes: 32-16, 16-8, 8-4, 4-2, 2-1, 1$0.5,0.50-0.25,0.25-0.125,0.125-0.075$ and $<0.075 \mathrm{~mm}$. Weight of each size fraction was recorded, and percent distribution of weight in each size was calculated.

For the determination of total metal concentrations in the different particle size fractions, the fractions were decomposed (digested) with a mixture of $\mathrm{HCl}(3 \mathrm{~mL})$ and $\mathrm{HNO}_{3}(9 \mathrm{~mL})$ in a CEM Mars 5 microprocessor controlled microwave oven with CEM HP 500 Teflon vessels (CEM corp., Matthews, USA) using USEPA method 3051 (USEPA, 1992). The cooled solutions were transferred to $100 \mathrm{~mL}$ volumetric flasks, and the solutions were diluted to volume with ultrapure water.
The ultrapure water was generated by an Elgastat Prima reverse osmosis and Elgastat Maxima ion exchange water purification system (Elga Ltd., Bucks, England). All reagents and acids were suprapure or pro analysis quality. The total element concentrations in each size fraction were determined with a Thermo Electron IRIS Intrepid II XDL Duo inductively coupled plasma optical emission spectrometer (Franklin, USA).

\section{Heavy metals determination in various digestion procedures}

In order to clarify the decomposition efficiency of metals in cyclone fly ash, different microwave-assisted acid digestion procedures were used, as well as the lithium tetraborate $\left(\mathrm{Li}_{2} \mathrm{~B}_{4} \mathrm{O}_{7}\right)$ fusion followed by dissolution in $12 \mathrm{~mL} \mathrm{HNO}_{3}(65 \%)$ and $40 \mathrm{~mL} \mathrm{H}_{2} \mathrm{O}$ (i.e. digestion procedure $\mathrm{F}$ in Table 1). Acid digestion procedures A to $\mathrm{E}$ were performed with a CEM Mars 5 microprocessor controlled microwave oven with CEM HP 500 Teflon vessels (CEM corp; Matthews, USA). For dissolution, $0.5 \mathrm{~g}$ of cyclone fly ash was weighted into the microwave oven digestion vessels (PFA, 100 $\mathrm{mL}$ ) and dissolved in those acid or acid mixtures given in digestion procedures A-E (Table 1). During the digestion, the temperature of the microwave oven was raised first to $165^{\circ} \mathrm{C}$ in $10 \mathrm{~min}$. (holding time $0 \mathrm{sec}$ ), then to $175^{\circ} \mathrm{C}$ in three minutes, where it was kept for 10 min. (max power $1200 \mathrm{~W}$, pressure control $20.68 \mathrm{bar}$ ). The cooled solutions were transferred to $100 \mathrm{~mL}$ volumetric flasks and the solutions were diluted to volume with ultrapure water.

In the fusion digestion (i.e. procedure F), the ash sample (0.25 g; d.w.) and 1.00 g lithium tetraborate $\left(\mathrm{Li}_{2} \mathrm{~B}_{4} \mathrm{O}_{7}\right)$ were weighed in a $10 \mathrm{~mL}$ platinum crucible, mixed carefully and covered finally with an additional $0.50 \mathrm{~g}$ of lithium tetraborate (i.e. total sample-flux ratio 1:6). After that, the crucible was placed in a Nabertherm B - 170 muffle furnace at $1000^{\circ} \mathrm{C}$ for $30 \mathrm{~min}$. (Nabertherm, Lilienthal/Brehmen, Germany). After heating, the molten content of the crucible was poured quickly to a $250 \mathrm{~mL}$ plastic bottle containing $12.5 \mathrm{~mL}$ concentrated $\mathrm{HNO}_{3}$ (65\%) and $40 \mathrm{~mL}$ ultrapure water. To complete the digestion, the plastic bottle was placed in ultrasonic bath $\left(70^{\circ} \mathrm{C}\right)$ until all of the solid material was completely dissolved. Finally, the content of the plastic bottle was quantitatively transferred to a $250 \mathrm{~mL}$ volumetric flask and diluted to volume with ultrapure water. The ultrapure water was generated by an Elgastat Prima reverse osmosis and Elgastat Maxima ion exchange 
water purification system (Elga Ltd, Bucks, England). All reagents and acids were suprapure or pro analysis quality. The total element concentrations in the ash samples were determined with a Thermo Electron IRIS Intrepid II XDL Duo inductively coupled plasma optical emission spectrometer (Franklin, USA).

\section{RESULTS AND DISCUSSION}

Physical and chemical properties of cyclone fly ash

According to Table 2, the $\mathrm{pH}$ of the cyclone ash was strongly alkaline ( $\mathrm{pH} 12.3)$. According to Van Herck and Vandecasteele (2001), an alkaline $\mathrm{pH}$ indicates that part of the dissolved metals occur as basic metal salts, oxides, hydroxides and/or carbonates. Thus, the proportions of soluble basic metal salts, oxides, hydroxides, and carbonates in the cyclone ash therefore outweigh the proportion of soluble acid components, and the cyclone ash subsequently generates an alkaline $\mathrm{pH}$. However, in this context it is worth noting that it is not self-evident that ash is alkaline. The $\mathrm{pH}$ of coal fly ash can vary from 4.5 to 12.5 depending largely on the $S$ content of the parent coal. Eastern U.S. coals, which contain anthracite, are generally high in $\mathrm{S}$ and produce acidic ashes, while western U.S. coals, which contain lignites, tend to be lower in $\mathrm{S}$ and higher in Ca and produce alkaline ashes (Page et al., 1979).

Furthermore, according to the electrical conductivity value $(42.3 \mathrm{mS} / \mathrm{cm})$, which is an index of the total dissolved electrolyte concentration, the leaching solution of the cyclone ash has a relatively high ionic strength, indicating that part of the dissolved metals occur as dissolved basic metal salts, e.g. oxides and hydroxides. The low total organic carbon (TOC) value of $1.6 \%$ (16 g/kg; d.w.) indicates that the cyclone ash contains almost no unburned organic material. The low loss on ignition (LOI) value (2.1\%) also supports this phenomenon. The low content of unburnable material in the cyclone ash indicates the efficiency of incineration in the grate-fired boiler. The content of unburnable organic material in fly ash is usually higher than in bottom ash (Kuokkanen et al., 2008). This phenomenon is probably due to the fact that fly ash particles that rise with the flue gases into the airpollution-control devices (e.g. cyclone, electrostatic precipitator) remain in the combustion chamber for a shorter time than those associated with the bottom ash fraction. The dry matter content (DMC) of the cyclone fly ash (99.8\%) was very high. This is disadvantage, and may increase the amount of dust during handling.

Particle size distribution of metals in the cyclone fly ash

As shown in Table 2, particles in the size range 32 to $0.5 \mathrm{~mm}$. were practically non-existent in the cyclone fly ash, and particles smaller than $0.075 \mathrm{~mm}$. accounted for $88.4 \%$ of the ash weight. This result indicates that cyclone fly ash consists of particles with a small diameter. This result is reasonable due to the fact that in the grate-fired boiler, the fuel is mechanically grinding in the moving grate firing system inside the furnace, resulting the small fly ash particles (Chimenos et al., 1999). The concentrations of heavy metals as a function of particle size are shown in Fig. 2 (i.e. USEPA digestion method 3051).

As shown in Fig. 2, the metals are enriched in small particles. With few exceptions, the enrichment trend is evident: the smaller the particle size, the higher the metal concentration. The highest concentrations for $\mathrm{Zn}, \mathrm{Cu}, \mathrm{Pb}, \mathrm{Cd}$ and $\mathrm{Mo}$ in the cyclone fly ash are found in the smallest particle size fraction $(<0.075 \mathrm{~mm}$.) and for rest of the heavy metals, in the second smallest particle size fraction $(0.075-0.125 \mathrm{~mm}$.). However, it is clear that for all metals, the smallest concentrations are found in the coarsest particle size fraction of 0.25-0.5 $\mathrm{mm}$. If we calculate the enrichment factor (EF) of metals, which is the ratio of the highest metal concentration to

Table 1: Procedures for metal digestion in cyclone fly ash in a microwave-oven using USEPA methods (i.e. procedures A to E) and by lithium tetraborate $\left(\mathrm{Li}_{2} \mathrm{~B}_{4} \mathrm{O}_{7}\right)$ fusion followed by acid dissolution (i.e. procedure $\mathrm{F}$ )

\begin{tabular}{|c|c|c|}
\hline Procedure & Digestion procedure & Reference \\
\hline A & $10 \mathrm{~mL} \mathrm{HNO}_{3}(65 \%)$ & USEPA 3051 \\
\hline B & $10 \mathrm{~mL} \mathrm{HNO}_{3}(65 \%)+2 \mathrm{~mL} \mathrm{H}_{2} \mathrm{O}_{2}(30 \%)$ & USEPA 3050B \\
\hline $\mathrm{C}$ & $9 \mathrm{~mL} \mathrm{HNO}_{3}(65 \%)+3 \mathrm{~mL} \mathrm{HCl}(35 \%)$ & USEPA 3051A \\
\hline $\mathrm{D}$ & $3 \mathrm{~mL} \mathrm{HF}(40 \%)+9 \mathrm{~mL} \mathrm{HNO}_{3}(65 \%)$ & USEPA 3052 \\
\hline $\mathrm{E}$ & $6 \mathrm{~mL} \mathrm{HCl}(35 \%)+2 \mathrm{~mL} \mathrm{HNO}_{3}(65 \%)+2 \mathrm{~mL} \mathrm{HF}(40 \%)$ & SFS-EN 13656 \\
\hline $\mathrm{F}$ & $\mathrm{Li}_{2} \mathrm{~B}_{4} \mathrm{O}_{7}$ followed by dissolution in $12 \mathrm{~mL} \mathrm{HNO}_{3}(65 \%)$ and $40 \mathrm{~mL} \mathrm{H}_{2} \mathrm{O}$ & ASTM 2001 \\
\hline
\end{tabular}


Int. J. Environ. Sci. Tech., 5 (4), 485-494, Autumn 2008

Table 2: Physical and chemical properties of cyclone fly ash and size distribution of particles in the ash as percentage of the mass

\begin{tabular}{lll}
\hline Property / particle size & Unit $^{{ }^{a}}$ & Cyclone fly ash \\
\hline Loss on ignition $\left(550^{\circ} \mathrm{C}\right)$ & $\%$ (d.w.) & 2.1 \\
Total organic carbon (TOC) & g/kg (d.w.) & 16 \\
Dry matter content $\left(105^{\circ} \mathrm{C}\right)$ & $\%$ & 99.8 \\
pH $(1: 2.5)$ & - & 12.3 \\
Electrical conductivity (EC) & $\mathrm{mS} / \mathrm{cm}$ & 42.3 \\
$0.5-32$ (mm.) & $\%$ & 0 \\
$0.25-0.5(\mathrm{~mm})$. & $\%$ & 0.65 \\
$0.125-0.25(\mathrm{~mm})$. & $\%$ & 2.9 \\
$0.075-0.125$ (mm.) & $\%$ & 7.7 \\
$<0.075(\mathrm{~mm})$. & $\%$ & 88.4 \\
\hline
\end{tabular}

${ }^{\mathrm{a}}$ Units are expressed on a dry weight (d.w.) basis

the lowest metal concentration, the following values: $\mathrm{Ba}$ (11), Cr (9.5), Cu (8.0), Cd (6.8), Zn (6.5), Co (5.7), V (4.5), Mo (3.2), Ni (2.9), Ni (2.9) and Pb (1.3) were obtained.

The results (Fig. 2 a-c and EF values) correspond well with the findings of Boman et al. (2004), who reported that cadmium, lead and zinc especially can be volatilized during combustion in all types of devices, including cyclones, and can be found as condensed species of fine particulate matter. The enrichment of metals in small particles could be explained by vaporization and condensation mechanism. According to Liao et al. (2007), some metals are volatilized in hightemperature combustion and then either condense or adsorb on the surface of smaller particles in flue gas as cooling occurs. These particles have a greater surface area to volume ratio than coarse particles. From a toxicological standpoint, the smallest particles are of the greatest concern when ash is handled at landfill disposal sites (i.e. in transport and disposal, particularly in stormy weather conditions), and some researches have reported risks to workers with prolonged exposure to ash (Chen et al., 2005; Cprek et al., 2007).

According to Sutherland (2003), the most important index of contamination is the mass loading of metals in different size fractions, which combines metal concentrations on a grain size basis with data on percentage of total mass. If the metal concentration for a given fraction is very high but it forms only a small portion of the overall sample mass, the contribution of this fraction to the total sample metal load will be minimal. The results in Table 3 indicate that between 87.9-94.4\% of the concentrations of all metals are detected in the finest fraction $(<0.075 \mathrm{~mm}$.). This means that the cyclone fly ash could be problematic during handling in landfill disposal sites as dusting could cause air pollution problems, e.g. the dust can be spread to a larger area with wind. Size distribution of the particles is an important factor that influences particle transportability. Particles with aerodynamic diameters under $0.1 \mathrm{~mm}$. can be transported by “suspension”, and the finest among them $(<0.01 \mathrm{~mm}$.) may remain airborne for periods (Wang et al., 2006).

\section{Comparison of digestion procedures}

According to the results presented in Fig. 1 (a, b), the widely used acid mixtures as well as the lithium tetraborate $\left(\mathrm{Li}_{2} \mathrm{~B}_{4} \mathrm{O}_{7}\right)$ gave widely varying results for heavy metals in cyclone fly ash. Thus, a careful choice of suitable digestion procedures for ash material is of great importance in order that correct results are obtained. In the Fig. 1, the digestion procedure C $(9 \mathrm{~mL}$ $65 \% \mathrm{HNO}_{3}+3 \mathrm{~mL} 35 \% \mathrm{HCl}$ ), was used which is the USEPA method 3051, as a reference for other digestion procedures. This means, that the recoveries obtained in the acid digestion procedures of $\mathrm{A}, \mathrm{B}, \mathrm{D}$ and $\mathrm{E}$, as well as in lithium tetraborate $\left(\mathrm{Li}_{2} \mathrm{~B}_{4} \mathrm{O}_{7}\right)$ fusion (procedure $\mathrm{F}$ ) are compared to the results obtained in the digestion procedure C (Fig. 1). Procedure $\mathrm{C}$ was chosen as a "reference", because it is used in determining the metal concentrations in different particle size fractions. Furthermore, procedure C (i.e. USEPA method 3051) is used daily in the laboratory for routine analysis.

According to the results (Fig. $1 \mathrm{a}, \mathrm{b}$ ), the digestion procedures with $\mathrm{HNO}_{3}$ alone (procedure $\mathrm{A}$ ) and with a mixture of $\mathrm{HNO}_{3}+\mathrm{H}_{2} \mathrm{O}_{2}$ (procedure B) slightly underestimated the $\mathrm{Ba}$ and $\mathrm{Zn}$ concentrations in the cyclone fly ash. This may be due to incomplete dissolution of these metals. However, the digestion procedures with mixture of $\mathrm{HNO}_{3}+\mathrm{HF}$ and $\mathrm{HNO}_{3}+\mathrm{HF}$ $+\mathrm{HCl}$ were relatively effective for some metals, because they gave $\mathrm{Zn}$ values $11.4 \%$ and $17.3 \%$ higher than the reference digestion procedure with a acid mixture of 9 $\mathrm{mL} \mathrm{HNO}_{3}(65 \%)+3 \mathrm{~mL} \mathrm{HCl}$ (35\%). Although the use 

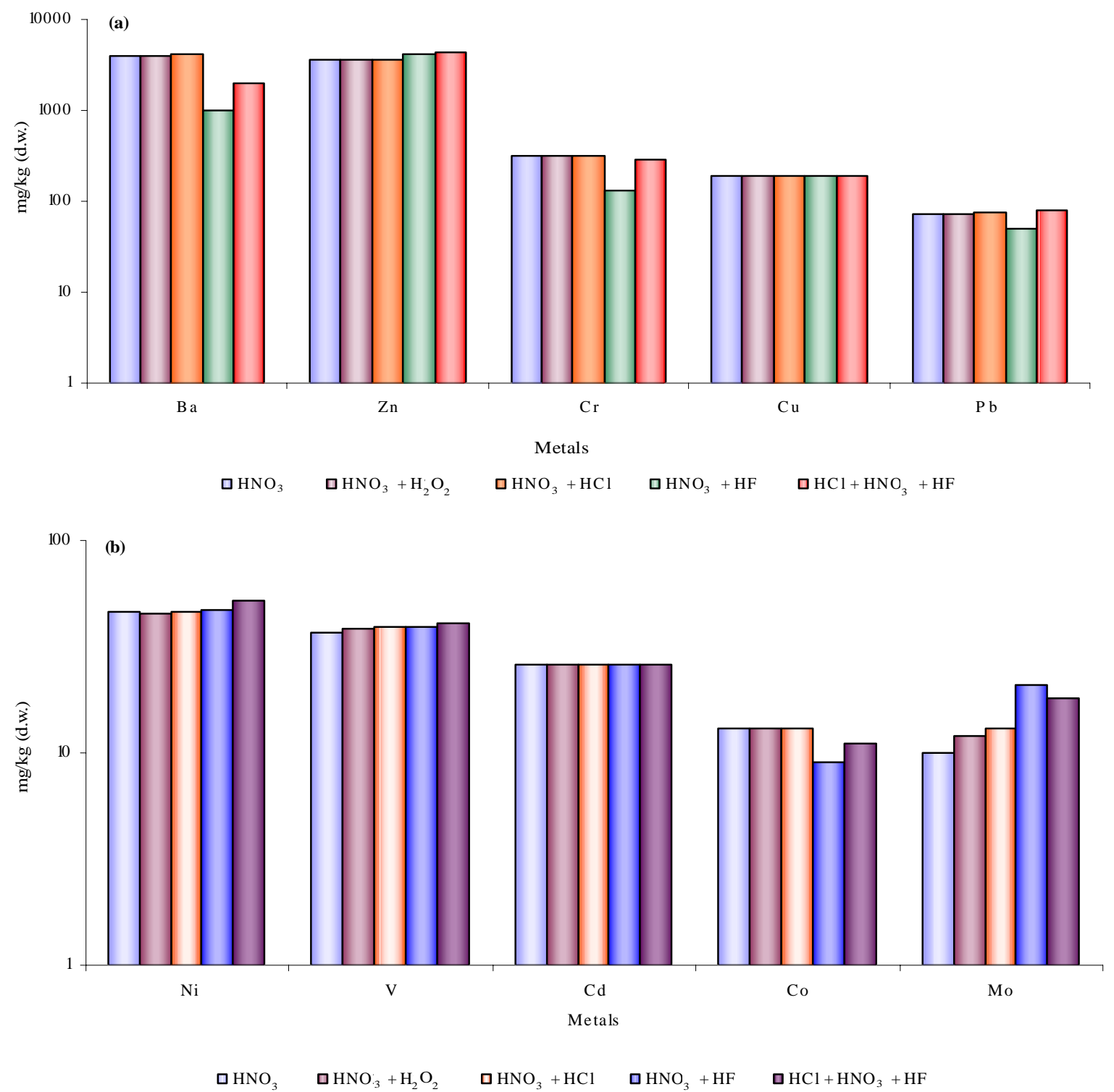

Fig. 1 (a, b): The recoveries of metal concentrations in cyclone fly ash after different dissolution procedures

of hydrofluoric acid is often necessary for the determination of a number of elements associated with siliceous minerals, its use can result in losses of trace elements during dissolution. For example, $\mathrm{HNO}_{3}+\mathrm{HF}$ and $\mathrm{HNO}_{3}+\mathrm{HF}+\mathrm{HCl}$ digestion procedures were ineffective at dissolving Ba from the cyclone fly ash, producing $76.4 \%$ and $52.7 \%$ lower Ba values than the reference procedure $\mathrm{C}$. The relatively low recoveries for many metals when using $\mathrm{HNO}_{3}+\mathrm{HF}$ and $\mathrm{HNO}_{3}+$
$\mathrm{HF}+\mathrm{HCl}$ digestion procedures is probably due to the formation of insoluble $\mathrm{CaF}_{2}$, which co-precipitate metals. This residue forms easily when calcium rich ash is dissolved using acid mixtures containing HF. This same phenomenon is reported by Sandroni and Smith (2002), who studied various microwave-oven assisted acid digestion procedures for sludge, soil and sediments. According to Lum et al. (1982), one possible reason for the high deficit of $\mathrm{Cr}$, when acid mixtures 
Int. J. Environ. Sci. Tech., 5 (4), 485-494, Autumn 2008
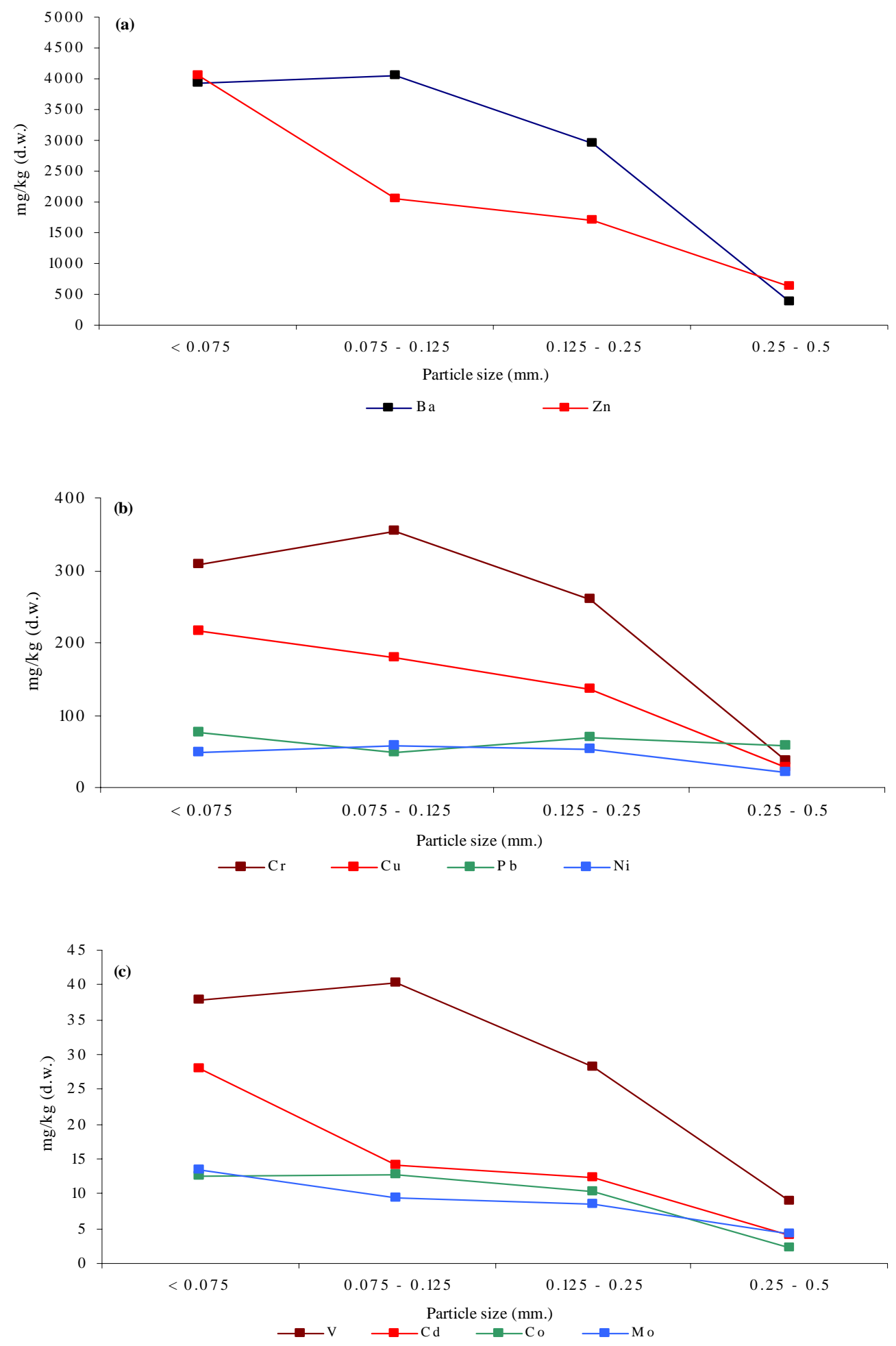

Fig. 2 (a-c): Metal concentrations in different particles size fractions 
Table 3: Metal mass loadings (\%) in different grain size fractions

\begin{tabular}{lllll}
\hline Metal & \multicolumn{4}{c}{ Size fraction $(\mathrm{mm})}$. \\
\hline & $<0.075$ & $0.075-0.125$ & $0.125-0.25$ & $0.25-0.5$ \\
\cline { 2 - 5 } $\mathrm{Ba}$ & 89.6 & 8.1 & 2.2 & 0.1 \\
$\mathrm{Zn}$ & 94.4 & 4.2 & 1.3 & 0.1 \\
$\mathrm{Cr}$ & 88.5 & 8.9 & 2.5 & 0.1 \\
$\mathrm{Cu}$ & 91.4 & 6.6 & 1.9 & 0.1 \\
$\mathrm{~Pb}$ & 91.7 & 5.0 & 2.8 & 0.5 \\
$\mathrm{Ni}$ & 87.9 & 8.8 & 3.1 & 0.2 \\
$\mathrm{~V}$ & 89.3 & 8.3 & 2.2 & 0.2 \\
$\mathrm{Cd}$ & 94.4 & 4.1 & 1.4 & 0.1 \\
$\mathrm{Co}$ & 89.6 & 7.9 & 2.4 & 0.1 \\
$\mathrm{Mo}$ & 92.3 & 5.5 & 1.9 & 0.3 \\
\hline
\end{tabular}

$\mathrm{HNO}_{3}+\mathrm{HF}$ and $\mathrm{HNO}_{3}+\mathrm{HF}+\mathrm{HCl}$ is used, is probably due to the formation of a low solubility chromyl fluoride $\left(\mathrm{CrO}_{2} \mathrm{~F}_{2}\right)$.

The results presented in Fig. 1 (a, b) also imply that the use of the alkali fusion procedure with lithium tetraborate $\left(\mathrm{Li}_{2} \mathrm{~B}_{4} \mathrm{O}_{7}\right)$ (i.e. procedure $\mathrm{F}$ ) gave clearly higher recoveries for $\mathrm{Ba}, \mathrm{Co}, \mathrm{Cr}, \mathrm{Cu}, \mathrm{Mo}, \mathrm{Ni}, \mathrm{V}$ and $\mathrm{Zn}$ than the acid procedure $\mathrm{C}\left(9 \mathrm{~mL} 35 \% \mathrm{HNO}_{3}+3 \mathrm{~mL}\right.$ $35 \% \mathrm{HCl})$. However, compared to the results obtained with the acid digestion methods, the recoveries of $\mathrm{Cd}$ and $\mathrm{Pb}$ at the alkali fusion procedure were very low. According to Yamashige et al. (1989), this phenomenon is caused by the volatilization of $\mathrm{Cd}$ and $\mathrm{Pb}$ at high temperatures during the procedure. It is also reported the same phenomenon when determining the heavy metal concentrations in total suspended particles (TSP) around a mining complex in Kemi in northern Finland (Pöykiö et al., 2002).

Although the recovery of "total" metal concentration is often needed, in environmental analytical chemistry it is often useful to acquire information on the bioavailable rather than the total elements present. Thus, various (acid) leaching procedures have become a common alternative to total digestion. Thus, according to Lamble and Hill (1998), in addition to the type of sample and elements to be determined the choice of sample digestion procedure may be influenced by a number of practical considerations. These may include the number of samples to be analysed, method of analysis, safety aspects, capital and operating costs of equipment, skills level of the operator, and the degree of accuracy and precision required. When choosing the appropriate digestion procedure, investigators may benefit from the decision flow chart developed by Sastre et al. (2002), in which the selection of digestion procedure is based on both the nature of the sample and the purpose of the analysis.

\section{CONCLUSIONS}

The particles in the cyclone fly ash were all smaller than $0.25 \mathrm{~mm}$. in diameter, and particles smaller than $0.075 \mathrm{~mm}$ in diameter accounted for $88.4 \%$ of the ash weight. This result indicates that cyclone fly ash consists of particles with a small diameter. The metals in the cyclone fly ash were enriched in small particles. The highest concentrations for $\mathrm{Zn}, \mathrm{Cu}, \mathrm{Pb}, \mathrm{Cd}$ and $\mathrm{Mo}$ in the cyclone fly ash were found in the smallest particle size fraction ( $<0.075 \mathrm{~mm}$.), and for $\mathrm{Ba}, \mathrm{Cr}, \mathrm{Ni}, \mathrm{V}$ and $\mathrm{Co}$ in the second smallest particle size fraction (0.075-0.125 $\mathrm{mm}$.). From environmental and toxicological standpoint, the smallest particles are of the greatest concern when ash is handled at landfill disposal sites (transport and disposal especially in stormy weather conditions) and some researches have reported risks to workers with prolonged exposure to ash. The results of the comparison of various dissolution methods for heavy metals showed that the digestion procedures with $\mathrm{HNO}_{3}$ alone (USEPA 3051) or with a mixture of $\mathrm{HNO}_{3}+$ $\mathrm{H}_{2} \mathrm{O}_{2}$ (USEPA 3050B) slightly underestimated the metal concentrations in the cyclone fly ash. Although the use of hydrofluoric acid (HF) is often necessary for the determination of a number of elements that are associated with siliceous minerals, its use can result in losses of trace elements during dissolution.

\section{ACKNOWLEDGEMENTS}

The authors wish to thank the technical staff of Suomen Ympäristöpalvelu Ltd, especially Ilkka Välimäki (M.Sc.), under whose supervision all the chemical analyses were performed. The authors are also grateful to the Estonian Academy of Sciences 
for enabling the implementation of this co-operation study by applying grants for a bilateral exchange programme visit to Tartu University in November 2007. Thanks are also due to Hanna Liikala for correcting the English language.

\section{REFERENCES}

ASTM, (2001). The American Society for Testing and Materials. Standard test method for major and trace elements in lime stone and lime by Inductively Coupled Plasma Atomic Emission Spectroscopy and Atomic Absorption. Designation C 1301-95. West Conshohocken. United States.

Boman, C.; Nordin, A.; Boström, D.; Öhman, M., (2004). Characterization of inorganic particulate matter from residential combustion of pelletized biomass fuels. Energ. Fuel., 18 (2), 338-348.

Chimenos, J. M.; Segarra, M.; Fernández, M.; Espiell, F., (1999). Characterization of the bottom ash in municipal solid waste incinerator. J. Hazard. Mater., 64 (3), 211-222.

Cprek, N.; Shah, N.; Huggins, F.; Hyffman, G., (2007). Computer controlled scanning electron microscopy (CCSEM) investigation of quarts in coal fly ash. Fuel Proc. Tech., 88 (11-12), 1017-1020.

Chen, Y.; Shah, N.; Huggins, F.; Huffman, G., (2005). Transmission electron microscopy investigation of ultrafine coal fly ash particles. Environ. Sci. Tech., 39 (4), 11441151.

Filgueiras, A. V.; Lavilla, J.; Bendicho, C., (2002). Chemical sequential extraction for metal partitioning in environmental solid samples. J. Environ. Monitor., 4 (6), 823-857.

Hlavay, J.; Polyak, K.; Wesemann, G., (1992). Particle size distribution of mineral phases and metals in dusts collected at different workplaces. Fresen. J. Anal. Chem., 344 (7-8), 319-321.

Kuokkanen, T.; Pöykiö, R.; Nurmesniemi, H.; Rämö, J., (2008). Chemical sequential extraction of heavy metals and sulphur in bottom ash and in fly ash from a pulp and paper mill complex. Waste Manage. Res., 26 (4), 389-399.

Lamble, K. J.; Hill, S. J., (1998). Microwave digestion procedures for environmental matrices, critical review. Analyst, 123, 103R-133R.

Liao, C.; Wu, C.; Yan, Y., (2007). The characteristics of inorganic elements in ashes from a $1 \mathrm{MW}$ CFB biomass gasification power generation plant. Fuel Proc. Tech., 88 (2), 149-156.

Lum, K. R.; Betteridge, J. S.; Macdonald, R. R.; (1982). The potential availability of $\mathrm{P}, \mathrm{Al}, \mathrm{Cd}, \mathrm{Co}, \mathrm{Cr}, \mathrm{Cu}, \mathrm{Fe}, \mathrm{Mn}, \mathrm{Ni}$, $\mathrm{Pb}$ and $\mathrm{Zn}$ in urban particulate matter. Environ. Tech. Lett., 3, 57-62.

Nurmesniemi, H.; Pöykiö, R.; Kuokkanen, T.; Perämäki, P.; Välimäki, I., (2005). Sequential leaching of trace elements in bottom ash from a fluidized bed co-combustion boiler at a pulp and paper mill complex. J. Solid Waste Manage. Tech., 31 (3), 115-121.

Osán, J.; Alföldy, B.; Török, S.; Van Grieken, R., (2002). Characterisation of wood combustion particles using electron probe microanalysis. Atmos. Environ. 36 (13), 2207-2214.

Page, A. L.; Elseewi, A.; Straughan, I., (1979). Physical and chemical properties of fly ash from coal-fired power plants with reference to environmental impacts. Residue Rev. 71, 83-120.

Pöykiö, R.; Torvela, H.; Perämäki, P.; Kuokkanen, T.; Rönkkömäki, H., (2000). Comparison of dissolution methods for multi-element analysis of some plant materials used as bioindicator of sulphur and heavy metal deposition determined by ICP-AES and ICP-MS. Analysis, 28 (9), 850-854.

Pöykiö, R.; Perämäki, P.; Bergström, R.; Kuokkanen, T.; Rönkkömäki, H., (2002). Assessment of the impact of opencast chrome mining on the ambient air concentrations of TSP, $\mathrm{Cr}, \mathrm{Ni}$ and $\mathrm{Pb}$ around a mining complex in Northern Finland. Intern. J. Environ. Anal. Chem., 82 (5), 307-319.

Pöykiö, R.; Perämäki, P., (2003). Acid dissolution methods for heavy metals determination in pine needles. Environ. Chem. Lett., 1 (3), 191-195.

Pöykiö, R.; Mäenpää, A.; Perämäki, P.; Niemelä, M.; Välimäki, I., (2004). Heavy metals ( $\mathrm{Cr}, \mathrm{Zn}, \mathrm{Ni}, \mathrm{V}, \mathrm{Pb}, \mathrm{Cd}$ ) in lingonberries (Vaccinium vitis-idaea L.) and assessment of human exposure in two-industrial areas in the Kemi-Tornio region, Northern Finland. Arch. Environ. Con. Tox., 48 (3), 338-343.

Pöykiö, R.; Perämäki, P.; Niemelä, M., (2005). The use of Scots pine (Pinus sylvestris L.) bark as a bioindicator for environmental pollution monitoring along two industrial gradients in the Kemi-Tornio area, northern Finland. Inter. J. Environ. Anal. Chem., 85 (2), 127-139.

SFS-EN, (2000a). The European standard SFS-EN 13037. Soil improvers and growing media. Determination of $\mathrm{pH}$. Finnish Standards Association SFS. Finnish Environment Institute, Helsinki.

SFS-EN, (2000b). The European standard SFS-EN 12880. Characterization of sludge. Determination of dry residue and water content. Finnish Standard Association SFS. Finnish Environmental Institute, Helsinki.

SFS-EN, (2000c). The European Standard SFS-EN 12879. Characterisation of sludge. Determination of loss on ignition of dry mass. Finnish Standards Association SFS. Finnish Environment Institute, Helsinki.

SFS-EN, (2001). The European Standard SFS-EN 13137. Characterisation of waste. Determination of total organic carbon in waste, sludge and sediments. Finnish Standards Association SFS. General Industry Federation of Finland, Helsinki.

SFS-EN, (2003). The European Standard SFS-EN 13656. Characterization of waste. Microwave assisted digestion with hydrofluoric acid, nitric acid and hydrochloric acid mixture of subsequent determination of elements. Finnish Standards Association SFS. General Industry Federation, Helsinki.

Sandroni, V.; Smith, C. M. M., (2002). Microwave digestion of sludge, soil and sediment samples for metal analysis by inductively coupled plasma atomic emission spectrometry. Anal. Chim. Acta, 468 (2), 335-344.

Sastre, J.; Sahuquillo, A.; Vidal, M.; Rauret, G., (2002). Determination of $\mathrm{Cd}, \mathrm{Cu}, \mathrm{Pb}$ and $\mathrm{Zn}$ in environmental samples: microwave assisted total digestion versus aqua regia and nitric acid extraction. Anal. Chim. Acta, 462 (1), 59-72.

Sutherland., R. A., (2003). Lead in grain size fractions of road-deposited sediment. Environ. Pollut. 21(2), 229237. 
USEPA, (1996). Acid digestion of sediments, sludge and soils. method 3050B, Washington DC, United States.

USEPA, (1992). Microwave assisted acid digestion of sediments, sludges, soils and oils. method 3051, Washington DC, USA.

USEPA, (1998). Microwave assisted acid digestion of sediments, sludges, soils and oils. method 3051A, Washington DC, USA.

USEPA, (1996). Microwave assisted acid digestion of siliceous and organically based matrices. method 3052, Washington DC, USA.

Van Herck, P.; Vandercasteele, C., (2001). Evaluation of the use of a sequential extraction procedure for the characterization and treatment of metal containing solid waste. Waste Manage., 21 (8), 685-694.

Wang, X. S.; Qin, Y.; Chen, Y. K., (2006). Heavy metals in urban roadside soils, part 1: effect of particle size fractions on heavy metals partitioning. Environ. Geo. 50 (7), 10611066.

Yamashige, T.; Yamamoto, M.; Sunahara, H., (1989). Comparison of decomposition methods for the analysis of atmospheric particulates by atomic absorption spectrometry. Analyst, 114, 1071-1077, doi: 10.1039/AN9891401071.

\section{AUTHOR (S) BIOSKETCHES}

Rönkkömäki, H., Ph.D., Head of laboratory, Finnish Institute of Occupational Health, Aapistie 1, FI-90220 Oulu, Finland. Email: hannu.ronkkomaki@ttl.fi

Pöykiö, R., Ph.D., Environmental manager, City of Kemi, The Town Planning and Building Committee, Environmental Research Division, Valtakatu 26, FI-94100 Kemi, Finland. Email: risto.poykio@kemi.fi

Nurmesniemi, H., Ph.D., Environmental manager, Stora Enso Oyj, Veitsiluoto Mill, FI-94800 Kemi, Finland. Email: hannu.nurmesniemi@storaenso.com

Popov, K., D.Sc., Professor, Moscow State University of Food Technologies, Volokolamskoye sh. 11, Moscow 125080, Russia. Email: ki-popov@mtu-net.ru

Merisalu, E., Dr., medical science, associate professor, Department of Public Health, University of Tartu, St. Ravila 19, 50411 Tartu, Estonia. Email: eda.merisalu@ut.ee

Tuomi, T., PhD, Team leader, Finnish Institute of Occupational Health, Arinatie 3, FI-00370 Helsinki, Finland. Email: tapani.tuomi@ttl.fi

Välimäki, I., M.Sc., Head of laboratory, Suomen Ympäristöpalvelu Oy, Kiilakiventie 1, FI-90250 Oulu, Finland. Email: ilkka.valimaki@suomenymparistopalvelu.fi

This article should be referenced as follows:
Rönkkömäki, H.; Pöykiö, R.; Popov, K.; Merisalu, E.; Tuomi, T.; Välimäki, I., (2008). Particle size distribution
and dissolution properties of metals in cyclone fly ash. Int. J. Environ. Sci. Tech., 5 (4), 485-494.

